\title{
Investigating Nonlinear Shoreline Multiperiod Change from Orthophoto Map Information by Using a Neural Network Model
}

\author{
Tienfuan Kerh, ${ }^{1}$ Hsienchang Lu, ${ }^{1}$ and Rob Saunders ${ }^{2}$ \\ ${ }^{1}$ Department of Civil Engineering, National Pingtung University of Science and Technology, Pingtung 91207, Taiwan \\ ${ }^{2}$ Faculty of Architecture, Design and Planning, University of Sydney, NSW 2006, Australia \\ Correspondence should be addressed to Tienfuan Kerh; tfkerh@gmail.com
}

Received 3 February 2014; Revised 31 March 2014; Accepted 31 March 2014; Published 27 April 2014

Academic Editor: Zhichun Yang

Copyright (c) 2014 Tienfuan Kerh et al. This is an open access article distributed under the Creative Commons Attribution License, which permits unrestricted use, distribution, and reproduction in any medium, provided the original work is properly cited.

\begin{abstract}
The effects of extreme weather and overdevelopment may cause some coastal areas to exhibit erosion problems, which in turn may contribute to creating disasters of varying scale, particularly in regions comprising islands. This study used aerial survey information from three periods $(1990,2001$, and 2010) and used graphical software to establish the spatial data of six beaches surrounding the island of Taiwan. An overlaying technique was then implemented to compare the sandy area of each beach in the aforementioned study periods. In addition, an artificial neural network model was developed based on available digitised coordinates for predicting coastline variation for 2015 and 2020. An onsite investigation was performed using a global positioning system for comparing the beaches. The results revealed that two beaches from this study may have experienced significant changes in total sandy areas under a statistical 95\% confidence interval. The proposed method and the result of this study may provide a valuable reference in follow-up research and applications.
\end{abstract}

\section{Introduction}

Problems related to global warming and rising sea levels have been the focus of related research in recent years, because such problems may cause various types of disaster, depending on the affected area's geographical location and land characteristics [1-3]. Furthermore, the melting of icebergs in the polar region as a result of the "greenhouse effect" may cause the gradual rising of sea levels and that may result in a loss of land area. In severe cases, this phenomenon can destroy an island country if no action is taken for preventing this type of gradually formed disaster. Other factors, such as extreme weather, tidal current, drifting sand, land subsidence, the estuarine effect, and industrial development, may also cause a complex process to affect a shoreline area $[4,5]$. Therefore, examining shoreline changes during various periods is worthwhile for understanding how to protect the environment and manage land.

Investigation of the shoreline change along populated coastal region usually involved problems with a very large scale, which will rely on a suitable model for increasing prediction accuracy. An early proposed schematic erosion prediction method by Bruun [6], showed that beach profile may be predicted from an empirical model. Following the same concept and by considering many factors such as wave motion, sediment transport, and sea bed conditions, various models are reported for studying different type of shoreline erosion problems $[7,8]$. Other aspects of these studies entailed focusing on the development of a numerical model with the aid of hydraulic modelling experiments for a specified coastal region, to simulate and predict the possibility of shoreline variation [9-12]. Relevant research has provided useful references for evaluating the suitability of designing or planning construction projects along shorelines.

The development of modern geographic information system (GIS) and aerial survey photographs at coastal zones can provide greater reliability and accuracy for analyzing and visualization. Thus, these methods are also frequently adopted recently for monitoring the shoreline [13-18]. However, this image based method may be costly and time consuming for collecting, rectifying, and transferring the information from photographs to digitalized map. Besides, some errors may be generated during the transferring process of the geometric complexity and fragmented patterns of 
coastlines. Nevertheless, this method does provide a possible solution for evaluating the shoreline change in different periods.

To avoid complicating model process, simple forecast methods such as end rate, linear regression, and robust parameter estimation, are widely used recently [19-21]. These methods are in general need to assume that the determination of future shorelines is based on modelling points on past shorelines, and a function form may be obtained for predicting shoreline change. In contrast, the recently developed neural network approach offers a good way for linking different types of data sets by learning, and the trained and verified model can then be used for prediction.

The neural network approach is extensively employed in various engineering fields including the application in coastal engineering due to its simplicity, flexibility, and effectiveness [22-25]. However, it can be seen that most of previous studies are focussed on forecasting tidal level and land use evolution patterns. There was a paper dealing with beach profile and shoreline features by using neural network and survey image [26], but the technique is used to delineate the shoreline. The application of this approach directly to predict shoreline variation in future years based on the model developed from available multiperiod orthophoto images is relatively difficult to find up to the present time [27]. Therefore, without going for shoreline complicated evolution process, the combination of using neural network with digitized spatial information from orthophoto images may be considered as a new way for nonlinear shoreline prediction and sand-beach area calculation.

The first stage of this study involved examining orthophoto survey maps, obtained from the Aerial Office of Taiwan's Forestry Bureau, produced in three years (1990, 2001, and 2010). Based on available information, nine major beaches around the island of Taiwan were examined for evaluating the sand-line variation during these periods by using AutoCAD, a computer software package used in many professions for drafting, designing, and modelling. The second stage entailed employing an artificial neural network from known sand-line coordinates (1990 and 2001) to develop a model for targeting the known sand-line coordinates (2010). After the capability of the model was verified, a new neural network model was developed based on data interpolated from coordinates for forecasting possible shoreline changes in 2015 and 2020. Calculations were performed on the total sandy areas for each of the beaches to confirm the significance of variation during these periods. The third and final stage involved an onsite investigation using a global positioning system (GPS) receiver to compare the beach data. Image treatment, model development, and result analysis regarding the research area are presented and discussed in detail in the following sections.

\section{Research Beaches and Treatment of Shoreline Survey Images}

The island of Taiwan is located at $120^{\circ}-122^{\circ}$ in longitude and $22^{\circ}-25^{\circ}$ in latitude, approximately $377 \mathrm{~km}$ north south and approximately $142 \mathrm{~km}$ east west. In addition, the length of shoreline is approximately $1,200 \mathrm{~km}$ in circumference. On the east side of Taiwan, because of mountains and cliffs situated near the coastal region, the slope of the sea bottom is steep, and sand beaches are relatively small in scale. Conversely, the slope of sand beaches along the west shoreline is not as substantial, because the mountains are farther away from the shoreline. In addition, because most of the rivers on the island of Taiwan flow west into the Taiwan Strait, a large amount of sand has accumulated in the estuarine region, extending the scale of sand beaches on this side. Some manmade factors, such as overdevelopment of land, overpumping of groundwater, and various economic activities in the coastal region, have caused acute shoreline erosion problems in recent years.

Figure 1 displays the locations of initially chosen nine major beaches (BH1-BH9) around the island of Taiwan. These nine beaches required a preliminary on-site investigation before digitising the beach survey images. By examining the aerial survey images over these periods, it was established that $\mathrm{BH} 7$ and $\mathrm{BH} 8$ exhibit extreme changes in the sandbeach regions. The causes may be attributed to typhoons, tidal effects, floating wood, garbage, contamination, or manmade structures. Regardless of the causes, the process of sand erosion and accretion has been disturbed in these two beaches, making them unsuitable for prediction by using a neural network model. Similarly, as a result of harbour engineering construction at $\mathrm{BH} 9$ during the study periods, the survey images demonstrate a sizeable difference in sand area for the three years. Therefore, the three beaches that exhibit extreme changes are omitted for further analysis in this study.

This study sought to obtain the earliest and highestquality images for each aerial survey map, representing the same year of investigation for the examined beaches. However, the quality of some of the images was not as reliable as desired, and the length of investigation time for each beach was not consistent. In considering the development of survey techniques, two types of images, aerial survey maps and orthophoto maps, were obtained for the three examined years $(1990,2001$, and 2010). The aerial survey map does not have a standard proportion, whereas the orthophoto map is an aerial photograph geometrically corrected so that the scale is uniform [28], having a fixed proportion of 1:5,000. Thus, these images required adjustment by using geographic information system (GIS) software to ensure that all images appear in the same proportion and at the same position during comparisons.

In applying the corrected images, the computer's graphical software package, AutoCAD, was used to digitise the survey maps and draw the sand line for each beach. Note that the coordinate system TWD67 was employed for the 1990 maps, whereas the coordinate system TWD97 was employed for the 2001 and 2010 maps [29]. Therefore, a conversion procedure was required for applying the global coordinate system to the surveying technique of the GPS. After unifying all of the images to the same coordinate system, the output 


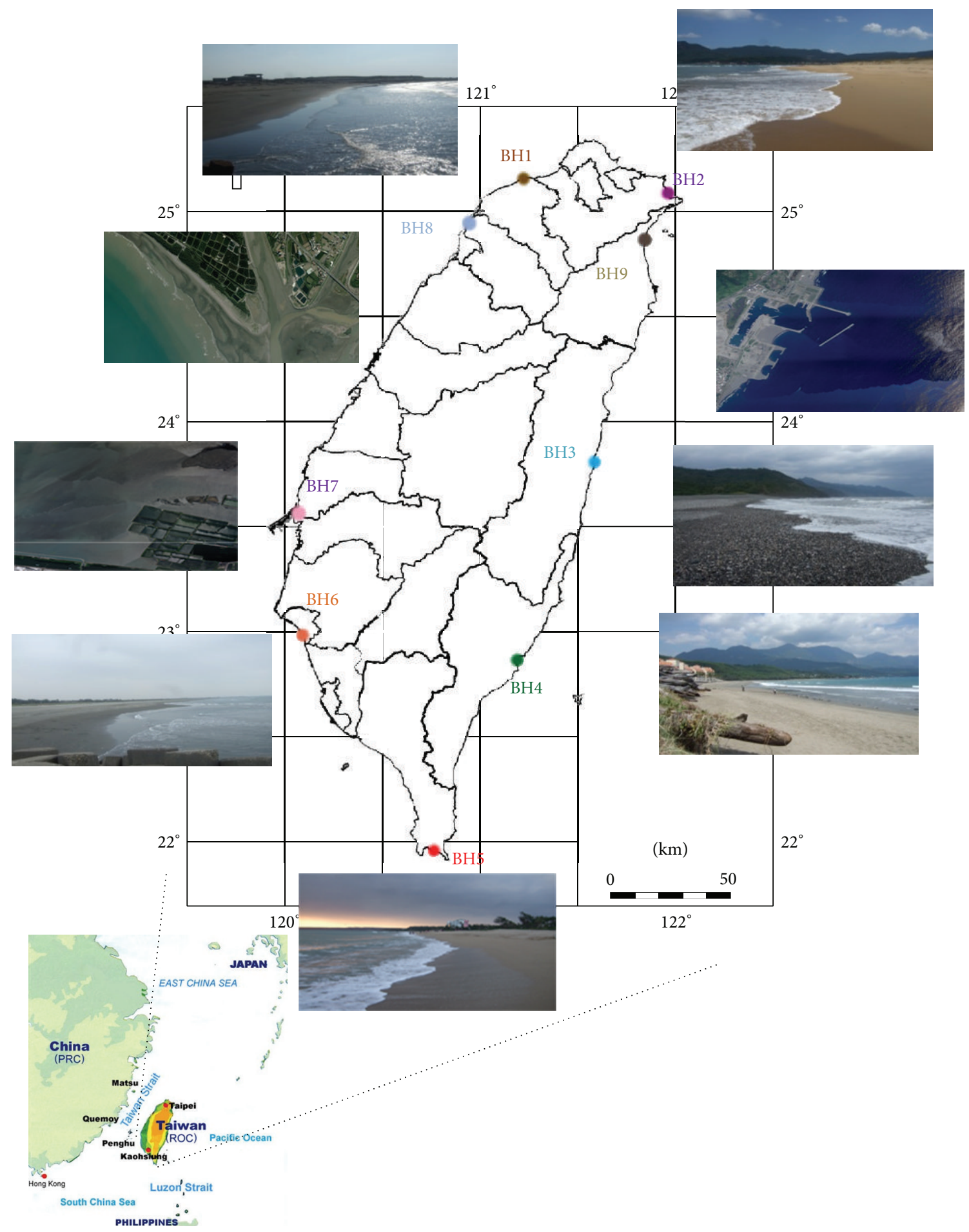

FIGURE 1: Location of research area and the chosen nine major beaches in the island of Taiwan (map source http://www.unc.edu/depts/ diplomat/item/2010/0912/comm/norris_quemoymatsu.html).

coordinates of each beach were then ready for analysis by using the spread sheet software Excel.

By loading the image into AutoCAD, the range of the sand line could be drawn for each beach for each given year. The set-fold function was then used to determine the shoreline variation of each beach. The set-fold function is not a mathematical equation but a computer technique for overlaying shorelines transparently. This method provides an easy way to compare the change of shorelines and to calculate the sandy areas in different years. Figure 2 shows an example (BH1) of six beaches that were investigated; the change of the sand region can be observed in the overlapping lines in 

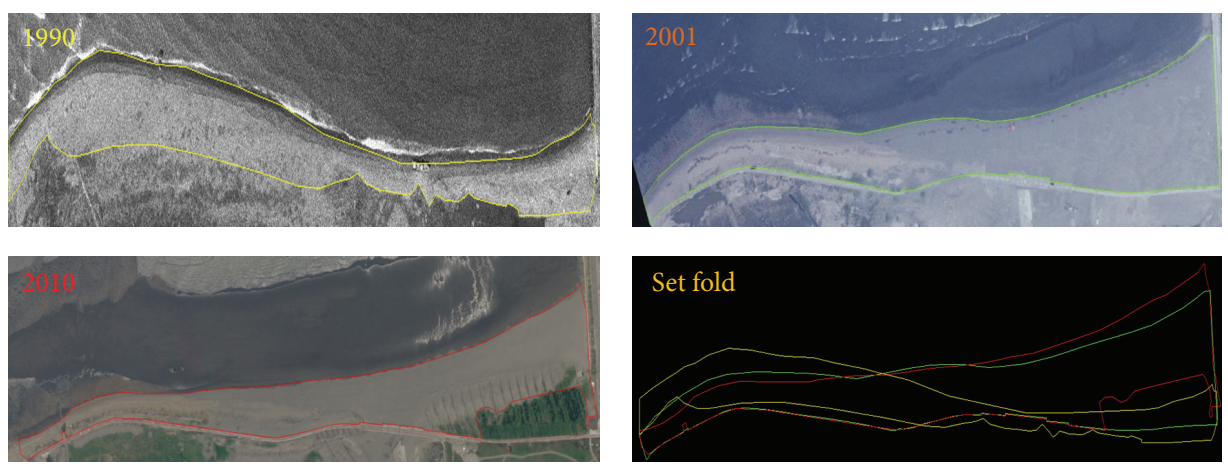

FIGURE 2: Variation of shoreline and sandy region for beach BH1 in multiperiod.

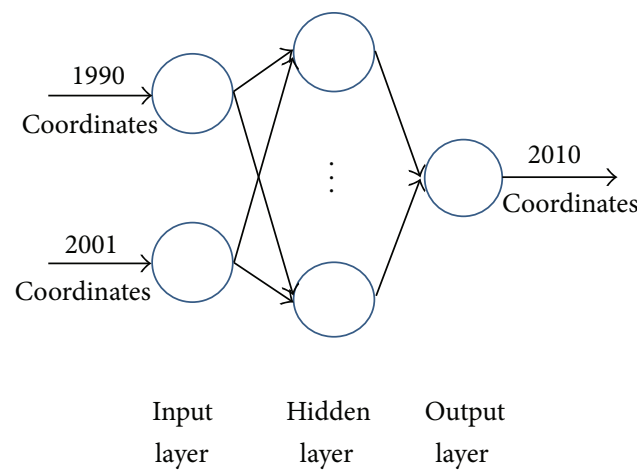

(a)

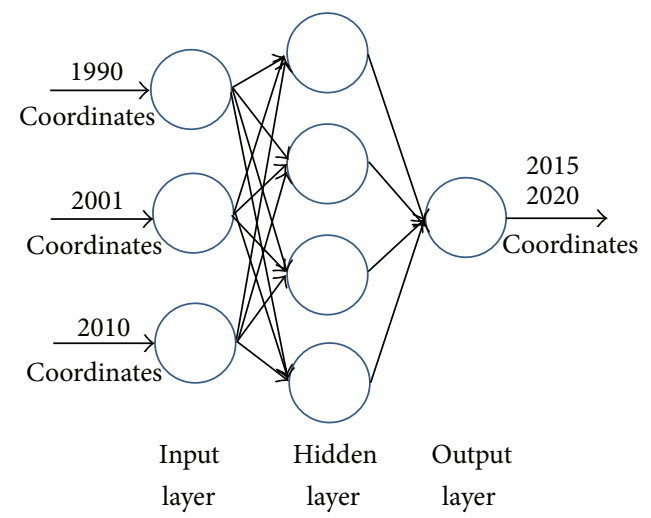

(b)

Figure 3: Structure of neural network models $\mathrm{I}_{2} \mathrm{H}_{n} \mathrm{O}_{1}$ (left) and $\mathrm{I}_{3} \mathrm{H}_{4} \mathrm{O}_{1}$ (right).

the figures. Based on this figure, the sandy areas of all of the beaches can also be calculated and compared with each other for the 3 given years.

\section{Comparison of Neural Network Models}

A neural network approach can be applied to solve various engineering problems, and a wide range of relevant literature [30-32] on the topic can be found. According to the theory of neural networks, the basic equation and evaluation index are briefly discussed in this paper. Regarding the multilayered neural network, the equation for each layer may be written as

$$
Y_{j}=F\left(\sum W_{i j} X_{i}-\theta_{j}\right),
$$

where $Y_{j}$ is the output of neuron $j, W_{i j}$ represents the connection weight from neuron $i$ to neuron $j, X_{i}$ is the input signal generated for neuron $i, \theta_{j}$ is the bias term associated with neuron $j$, and $F(x)=1 /\left(1+e^{-x}\right)$ is the commonly used nonlinear activation function.
The performance of a neural network model can generally be evaluated using the following two equations:

$$
\begin{gathered}
\mathrm{CC}=\frac{\sum_{i=1}^{m}\left(x_{i}-\bar{x}\right)\left(y_{i}-\bar{y}\right)}{\sqrt{\sum_{i=1}^{m}\left(x_{i}-\bar{x}\right)^{2} \sum_{i=1}^{m}\left(y_{i}-\bar{y}\right)^{2}}}, \\
\text { RMSE }=\sqrt{\sum_{n}^{N} \frac{\left(T_{n}-Y_{n}\right)^{2}}{N}},
\end{gathered}
$$

where CC is the coefficient of correlation, $x_{i}$ and $\bar{x}$ are the recorded value and its average value, respectively, $y_{i}$ and $\bar{y}$ are the estimated value and its average value, respectively, and $m$ denotes the number of data points in the analysis. In addition, RMSE is the root-mean-square error, $N$ is the number of learning cases, $T_{n}$ is the target value for case $n$, and $Y_{n}$ is the output value for case $n$.

Figure 3 shows a diagram of the neural network models used in this study. The model on the left side uses coordinated information of the years 1990 and 2001 as the inputs and the coordinates of the year 2010 as the target values. Different numbers of neurons in the hidden layer are used to verify the performance of the neural network model based on the coefficient of correlation and root-mean-square error. Because these inputs and outputs are all known coordinates from survey maps, the test result may verify the ability of 
TABLE 1: Performance $\left(\mathrm{CC}^{2}\right)$ of neural network models under different data arrangements.

\begin{tabular}{|c|c|c|c|c|c|c|c|c|c|}
\hline \multirow{2}{*}{ NN model } & \multicolumn{3}{|c|}{$\mathrm{I}_{2} \mathrm{H}_{2} \mathrm{O}_{1}$ (Type 1) } & \multicolumn{3}{|c|}{$\mathrm{I}_{2} \mathrm{H}_{3} \mathrm{O}_{1}$ (Type 1 ) } & \multicolumn{3}{|c|}{$\mathrm{I}_{2} \mathrm{H}_{4} \mathrm{O}_{1}$ (Type 1) } \\
\hline & $\mathrm{TN}$ & VF & TS & $\mathrm{TN}$ & VF & TS & $\mathrm{TN}$ & VF & TS \\
\hline Averaged CC ${ }^{2}$ & 0.9786 & 0.9728 & 0.9723 & 0.9861 & 0.9771 & 0.9764 & 0.9864 & 0.9806 & 0.9803 \\
\hline \multirow{2}{*}{$\mathrm{NN}$ model } & \multicolumn{3}{|c|}{$\mathrm{I}_{2} \mathrm{H}_{2} \mathrm{O}_{1}$ (Type 2) } & \multicolumn{3}{|c|}{$\mathrm{I}_{2} \mathrm{H}_{3} \mathrm{O}_{1}($ Type 2$)$} & \multicolumn{3}{|c|}{$\mathrm{I}_{2} \mathrm{H}_{4} \mathrm{O}_{1}$ (Type 2) } \\
\hline & $\mathrm{TN}$ & $\mathrm{VF}$ & TS & $\mathrm{TN}$ & $\mathrm{VF}$ & TS & TN & VF & TS \\
\hline Averaged CC ${ }^{2}$ & 0.9760 & 0.9767 & 0.9750 & 0.9861 & 0.9901 & 0.9878 & 0.9873 & 0.9927 & 0.9831 \\
\hline
\end{tabular}

TABLE 2: Calculated root-mean-square errors for each beach with the use of different models.

\begin{tabular}{|c|c|c|c|c|c|c|c|}
\hline \multirow{2}{*}{ NN model (Type 1) } & \multicolumn{6}{|c|}{ RMSE } & \multirow{2}{*}{ Averaged RMSE } \\
\hline & $\mathrm{BH} 1$ & $\mathrm{BH} 2$ & $\mathrm{BH} 3$ & $\mathrm{BH} 4$ & BH5 & BH6 & \\
\hline $\mathrm{I}_{2} \mathrm{H}_{2} \mathrm{O}_{1}$ & 0.0101 & 0.0101 & 0.0867 & 0.0195 & 0.0163 & 0.0090 & 0.0253 \\
\hline $\mathrm{I}_{2} \mathrm{H}_{3} \mathrm{O}_{1}$ & 0.0067 & 0.0039 & 0.0717 & 0.0155 & 0.0146 & 0.0056 & 0.0197 \\
\hline $\mathrm{I}_{2} \mathrm{H}_{4} \mathrm{O}_{1}$ & 0.0062 & 0.0024 & 0.0703 & 0.0152 & 0.0108 & 0.0056 & 0.0184 \\
\hline \multirow{2}{*}{ NN model (Type 2) } & \multicolumn{6}{|c|}{ RMSE } & \multirow{2}{*}{ Averaged RMSE } \\
\hline & BH1 & $\mathrm{BH} 2$ & $\mathrm{BH} 3$ & BH4 & BH5 & BH6 & \\
\hline $\mathrm{I}_{2} \mathrm{H}_{2} \mathrm{O}_{1}$ & 0.0098 & 0.0097 & 0.0878 & 0.0215 & 0.0158 & 0.0060 & 0.0251 \\
\hline $\mathrm{I}_{2} \mathrm{H}_{3} \mathrm{O}_{1}$ & 0.0065 & 0.0038 & 0.0678 & 0.0169 & 0.0145 & 0.0056 & 0.0192 \\
\hline $\mathbf{I}_{2} \mathbf{H}_{4} \mathbf{O}_{1}$ & 0.0069 & 0.0023 & 0.0656 & 0.0159 & 0.0106 & 0.0056 & 0.0178 \\
\hline
\end{tabular}

TABLE 3: Comparison of actual sandy area and estimated sandy area in the year of 2010.

\begin{tabular}{|c|c|c|c|c|c|}
\hline 2010 Beach & $\begin{array}{l}\text { Actual sandy area } \\
\qquad\left(\mathrm{m}^{2}\right)\end{array}$ & $\begin{array}{c}\mathrm{I}_{2} \mathrm{H}_{4} \mathrm{O}_{1}(\text { Type } 1) \\
\text { Estimated area }\left(\mathrm{m}^{2}\right)\end{array}$ & $\begin{array}{c}\text { Type } 1 \text { error } \\
(\%)\end{array}$ & $\begin{array}{c}\left.\mathrm{I}_{2} \mathrm{H}_{4} \mathrm{O}_{1} \text { (Type } 2\right) \\
\text { Estimated area }\left(\mathrm{m}^{2}\right)\end{array}$ & $\begin{array}{c}\text { Type } 2 \text { error } \\
(\%)\end{array}$ \\
\hline $\mathrm{BH} 1$ & 31589 & 31471 & 0.373 & 31539 & 0.159 \\
\hline $\mathrm{BH} 2$ & 218476 & 218162 & 0.144 & 218118 & 0.163 \\
\hline $\mathrm{BH} 3$ & 99883 & 96311 & 3.577 & 99308 & 0.576 \\
\hline $\mathrm{BH} 4$ & 95079 & 96867 & 1.881 & 98657 & 3.763 \\
\hline BH5 & 69844 & 70855 & 1.447 & 69908 & 0.092 \\
\hline BH6 & 408235 & 407557 & 0.166 & 408042 & 0.047 \\
\hline
\end{tabular}

the developed model, and a relatively more favourable result may be obtained for the beaches. The model on the right side, with four neurons in the hidden layer, is then observed for analysis, and an extension for including three input parameters is performed to predict the sand line of each beach in 2015 and 2020. The performance of neural network models and the prediction results are illustrated as in the following tables and figures.

For each beach, the original coordinates along the shoreline have 1,000 points, where 100 evenly distributed points were used for developing the neural network model. Two types of data sets-Type 1: 60\%-30\%-10\% and Type 2: 70\%$20 \%-10 \%$, with coordinate data randomly divided into three groups-were used for training (TN), verification (VF), and testing (TS) the model, respectively. Table 1 displays the averaged square value of the correlation coefficient at different stages of calculation for the two types of data arrangement. It was found that all of the models can obtain a satisfactory performance because all $\mathrm{CC}^{2}$ values are over 0.9 , indicating a high relationship between actual data and neural network estimation. Note that the model with four neurons in the hidden layer, in the type of data arrangement where $70 \%$ is used for training, 20\% for verification, and $10 \%$ for testing, achieves a relatively improved performance (slightly higher
$\mathrm{CC}^{2}$ values) over that of the other models. Furthermore, based on the calculated root-mean-square errors shown in Table 2, the same model exhibits the smallest averaged RMSE, calculated at 0.0178 . Therefore, this neural network model is preferable for the shoreline cases studied herein.

Table 3 shows a comparison of the performance of neural network models in the sandy areas of each beach. The numerical result indicated that the aforementioned, preferable model $\mathrm{I}_{2} \mathrm{H}_{4} \mathrm{O}_{1}$ (Type 2) can obtain a more accurate result in most of the beach cases. The average percentage error for the six beaches is $0.800 \%$ for using data arrangement, $70 \%$ for training, $20 \%$ for verification, and $10 \%$ for testing the model (Type 2), which is an improvement over that of the percentage error of $1.265 \%$ for model $\mathrm{I}_{2} \mathrm{H}_{4} \mathrm{O}_{1}$, which uses $60 \%$ for training, $30 \%$ for verification, and $10 \%$ for testing the Type 1 model. Therefore, this preferred neural network model was used for the shoreline prediction of each beach.

\section{Prediction of Shoreline Variation and Onsite Investigation}

The data in the previous section prove that using previous shoreline information $(1990,2001)$ in the neural network 

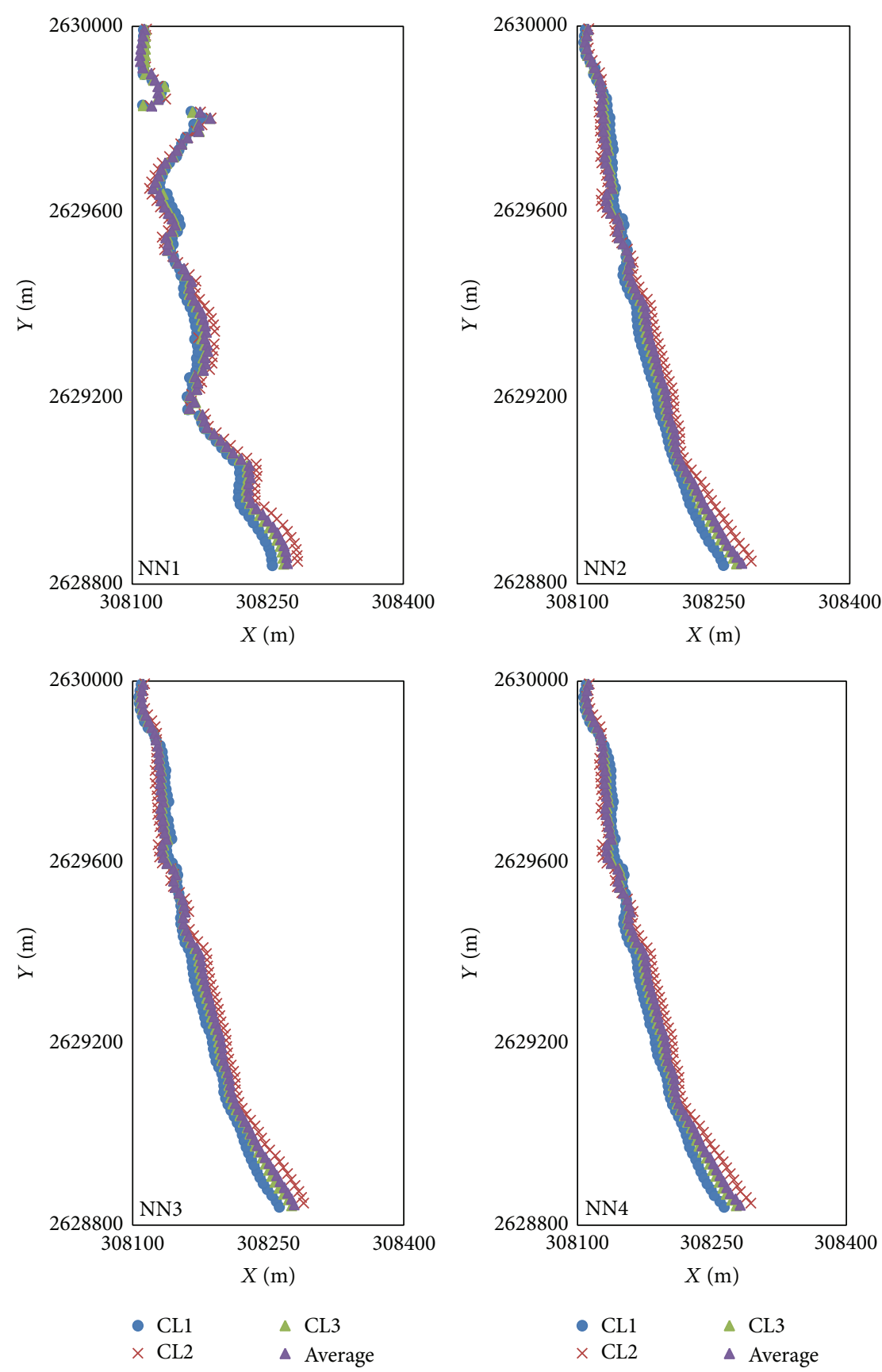

FIGURE 4: Comparison of neural network models for predicting beach BH3 in 2015.

model can accurately predict a future shoreline change (2010). For forecasting shoreline variation in the given future years (2015 and 2020), basic reference shoreline coordinates were required for developing a neural network model, by interpolating shoreline coordinates from previous years for the four models: NN1 (1990 and 2001); NN2 (2001 and 2010); NN3 (1990 and 2010); and NN4 (1990, 2001, and 2010). The coordinated differences (CL1, CL2, CL3, and the average) in shoreline of each beach from these years can help to yield reference data as well as developing a new neural network model for forecasting work.
To verify the newly developed neural network model, the model exhibiting the lowest performance, at $\mathrm{BH} 3$, is used as an example, and the comparative result is shown in Figure 4. The prediction results show that model NN1 demonstrated the worst performance, exhibiting a discontinuity at some points, whereas all of the other models exhibit a smooth prediction result. Model NN4 $\left(\mathrm{I}_{3} \mathrm{H}_{4} \mathrm{O}_{1}\right.$, see structure diagram in Figure 4), which uses information from 3 previous years, demonstrated slightly improved performance and more stability than the other models did. Therefore, this model was used for other beaches and for additional comparisons. 

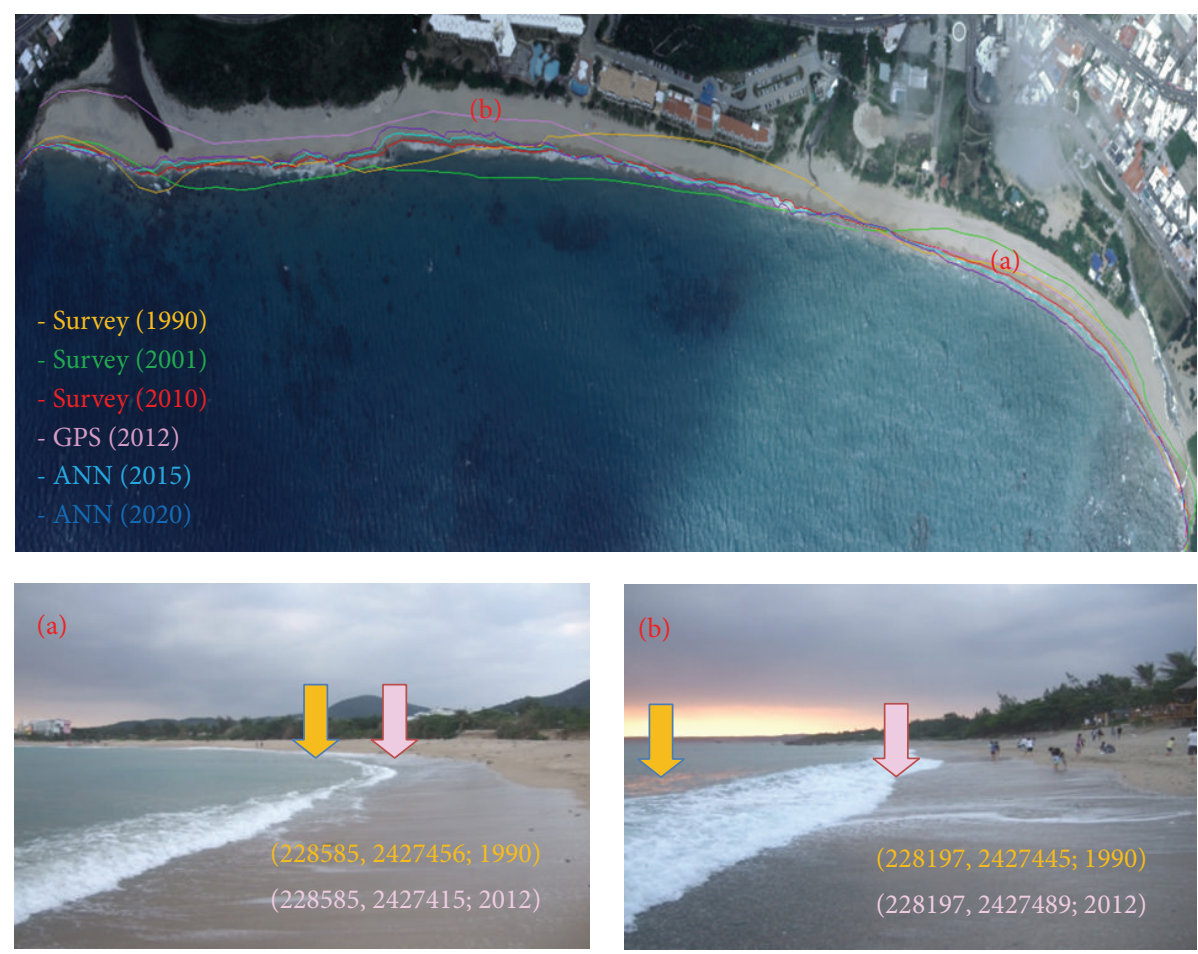

FIGURE 5: Shoreline change in different years and onsite beach condition for beach BH5.

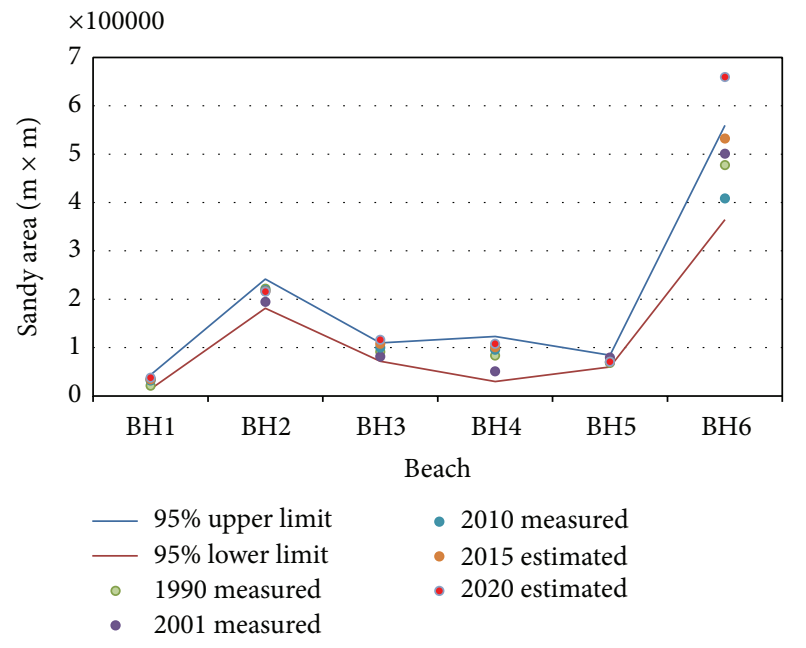

FIGURE 6: Total sandy area for each beach in different years.

For this study, observing the current shoreline condition for each beach was essential. An onsite assessment using a GPS receiver (GPSmap 60CSx manufactured by Garmin Corp.) was performed in 2012. An example of shoreline change according to year for each beach is shown in Figure 6. Based on the results for all six beaches, an accretion phenomenon is found in $\mathrm{BH}$; both erosion and accretion phenomena occurred in $\mathrm{BH} 2, \mathrm{BH} 4, \mathrm{BH}$, and $\mathrm{BH} 6$, whereas $\mathrm{BH} 3$ has a serious erosion problem during the studied period.

The shoreline for each beach may experience erosion or accretion at different local regions. Therefore, calculating the total sandy area is essential for examining the change of the nonlinear coastline. Figure 6 shows that the total sandy area for the six beaches in each year is below a $95 \%$ confidence interval. All of the survey data $(1990,2001$, and 2010) show that the total sandy areas are situated within the upper and lower limits; that is, there is no statistically significant change in sandy area for any beach (see Figure 5). However, including the future-predicted data (2015 and 2020) in the calculation involving neural network models reveals that at two beaches, $\mathrm{BH} 3$ and $\mathrm{BH} 6$, the total sandy area for the former may slightly exceed the limit, whereas the latter may significantly exceed the upper limit in 2020.

The results presented in this study may indicate that the erosion problem under current conditions is not acute in the beaches studied herein. However, the investigation period from 1990 to 2020 covers only 30 years. Presently, the effects of global warming and rising sea levels may still have influenced shoreline change in the Taiwan region; the shoreline must be monitored as often as possible to prevent negative impacts.

\section{Conclusion}

Natural disasters near coastline regions can include earthquake-induced tsunamis, typhoons, and flooding. These disasters may cause instantaneous damage to structures and may inflict harm to humans. Conversely, shoreline erosion problems are gradual, which may cause loss of land area and may endanger the existence of a country that comprises mostly islands that do not rise much above sea level. Therefore, examining shoreline change is worthwhile when considering both global warming and local concerns. 
Three methods were used in this study to examine shoreline change problems on the island of Taiwan: (1) comparing the difference in the shorelines by using multiperiod survey maps; (2) developing a neural network model according to digitised coordinates for predicting possible variations; and (3) performing an onsite investigation by using a GPS receiver. Based on the beaches studied, the results show that sand erosion and accretion exist in some local regions of each beach, but the total sandy area of each beach has not significantly changed under a $95 \%$ statistical confidence interval. However, the prediction results show that two beaches have the potential to experience an increase in their sand areas in future years.

By avoiding complex procedures, this study used the most basic method possible to examine shoreline change problems. Therefore, only the factor of time (i.e., multiperiod aerial survey maps) was considered in the comparison analysis and model development. The reliability of the results obtained might be questionable, but other influencing events on shoreline change, such as wave motion, sea current, tide rise and fall, and land use in watersheds, all occur over time and, hence, should be included in the time factor. Therefore, this study provides a valuable reference for the examined region and may be applicable to other coastlines of interest worldwide.

\section{Conflict of Interests}

The authors declare that there is no conflict of interests regarding the publication of this paper.

\section{Acknowledgments}

Support from the National Science Council under Project no. NSC102-2221-E-020-027 is greatly appreciated. The Aerial Office, Forestry Bureau of Taiwan, is also acknowledged for providing the orthophoto images and aerial survey maps. Additionally, the editing work to improve the usage of English by Bill Thornton is acknowledged.

\section{References}

[1] A. E. Carlson and K. Winsor, "Northern hemisphere ice-sheet responses to past climate warming," Nature Geoscience, vol. 5, pp. 607-613, 2012.

[2] C. A. Thatcher, J. C. Brock, and E. A. Pendleton, "Economic vulnerability to sea-level rise along the Northern U.S. gulf coast," Journal of Coastal Research, vol. 63, pp. 234-243, 2013.

[3] P. N. DiNezio and J. E. Tierney, "The effect of sea level on glacial indo-pacific climate," Nature Geoscience, vol. 6, pp. 485-491, 2013.

[4] Y. F. Chiu, "Coastal erosion and protection strategy in Taiwan," Civil Technology, vol. 3, no. 3, pp. 102-110, 1999.

[5] M. Y. Hsu, "A study on the coastal erosion and backward at east side of Taiwan," Civil Technology, vol. 2, no. 3, pp. 64-89, 1999.

[6] P. Bruun, "Sea level rise as a cause of shore erosion," Journal of Waterways and Harbors Division, vol. 88, pp. 117-133, 1962.

[7] D. L. Kriebel, Beach Erosion Model (EBEACH) Users Manual: Theory and Background, vol. 2, Division of Beaches and Shores,
Florida Department of Natural Resources, Tallahassee, Fla, USA, 1984

[8] G. Masselink and A. D. Short, "The effect of tide range on beach morphodynamics and morphology: a conceptual beach model," Journal of Coastal Research, vol. 9, no. 3, pp. 785-800, 1993.

[9] Ó. Ferreira, T. Garcia, A. Matias, R. Taborda, and J. A. Dias, "An integrated method for the determination of set-back lines for coastal erosion hazards on sandy shores," Continental Shelf Research, vol. 26, no. 9, pp. 1030-1044, 2006.

[10] A. Jadidi, M. A. Mostafavi, Y. Bédard, B. Long, and E. Grenier, "Using geospatial business intelligence paradigm to design a multidimensional conceptual model for efficient coastal erosion risk assessment," Journal of Coastal Conservation, vol. 17, pp. 527-543, 2013.

[11] D. L. Millar, H. C. M. Smith, and D. E. Reeve, "Modelling analysis of the sensitivity of Shoreline change to a wave farm," Ocean Engineering, vol. 34, no. 5-6, pp. 884-901, 2007.

[12] T. M. Ravens, B. M. Jones, J. Zhang, C. D. Arp, and J. A. Schmutz, "Process-based coastal erosion modeling for drew point, North Slope, Alaska," Journal of Waterway, Port, Coastal and Ocean Engineering, vol. 138, no. 2, pp. 122-130, 2012.

[13] J. O. Adegoke, M. Fageja, James, G. Agbaje G, and T. E. Ologunorisa, "An assessment of recent changes in the niger delta coastline using satellite imagery," Journal of Sustainable Development, vol. 3, no. 4, pp. 277-296, 2010.

[14] A. A. Alesheikh, A. Ghorbanali, and N. Nouri, "Coastline change detection using remote sensing," International Journal of Environmental Science and Technology, vol. 4, no. 1, pp. 6166, 2007.

[15] F. A. Armah, "GIS-based assessment of short term Shoreline changes in the coastal erosion-sensitive zone of Accra, Ghana," Journal of Environmental Sciences, vol. 5, no. 7, pp. 643-654, 2011.

[16] C. Fletcher, J. Rooney, M. Barbee, S.-C. Lim, and B. Richmond, "Mapping Shoreline change using digital orthophotogrammetry on Maui, Hawaii," Journal of Coastal Research, no. 38, pp. 106-124, 2003.

[17] A. Guariglia, A. Buonamassa, A. Losurdo et al., "A multisource approach for coastline mapping and identification of Shoreline changes," Annals of Geophysics, vol. 49, no. 1, pp. 295-304, 2006.

[18] H. W. Wang, C. T. Wang, K. S. Chen, and Y. L. Lin, "Analysis change detection waterline in West Taiwan using satellite SAR imagery," Journal of Photogrammetry and Remote Sensing, vol. 12, no. 2, pp. 107-119, 2007.

[19] B. C. Douglas and M. Crowell, "Long-term Shoreline position prediction and error propagation," Journal of Coastal Research, vol. 16, no. 1, pp. 145-152, 2000.

[20] M. S. Fenster, R. Dolan, and J. F. Elder, "A new method for predicting Shoreline positions from historical data," Journal of Coastal Research, vol. 9, no. 1, pp. 147-171, 1993.

[21] R. M. Goncalves, J. L. Awange, C. P. Krueger, B. Heck, and L. S. Coelho, "A comparison between three short-term Shoreline prediction models," Ocean and Coastal Management, vol. 69, pp. 102-110, 2012.

[22] H.-K. Chang and L.-C. Lin, "Multi-point tidal prediction using artificial neural network with tide-generating forces," Coastal Engineering, vol. 53, no. 10, pp. 857-864, 2006.

[23] S. Karimi, O. Kisi, J. Shiri, and O. Makarynskyy, "Neuro-fuzzy and neural network techniques for forecasting sea level in Darwin Harbor, Australia," Computers and Geosciences, vol. 52, pp. 50-59, 2013. 
[24] J. O. Pierini, M. Lovallo, L. Telesca, and A. Gómez, "Investigating prediction performance of an artificial neural network and a numerical model of the tidal signal at Puerto Belgrano, Bahia Blanca Estuary (Argentina)," Acta Geophysica, vol. 61, no. 6, pp. 1522-1537, 2013.

[25] J. Rocha, J. C. Ferreira, J. Simões, and J. A. Tenedório, "Modelling coastal and land use evolution patterns through neural network and cellular automata integration," Journal of Coastal Research, no. 50, pp. 827-831, 2007.

[26] T. W. Ryan, P. J. Sementilli, P. Yuen, and B. R. Hunt, "Extraction of Shoreline features by neural nets and image processing," Photogrammetric Engineering \& Remote Sensing, vol. 57, no. 7, pp. 947-955, 1991.

[27] T. Kerh, G. S. Hsu, and D. Gunaratnam, "Forecasting of nonlinear Shoreline variation based on aerial survey map by neural network approach," International Journal of Nonlinear Sciences and Numerical Simulation, vol. 10, no. 9, pp. 1211-1221, 2009.

[28] Wikipedia, "Orthophoto," Wikimedia Foundation, 2013, https:// en.wikipedia.org/wiki/Orthophoto.

[29] L. F. Chen, L. G. Chen, and F. Yuen, Transformation Design and Application of TWD97 Coordinate System, Aerial Office, Forestry Bureau, 2002.

[30] A. I. Galushkin, Neural Networks Theory, Springer, Berlin, Germany, 2007.

[31] M. Y. Rafiq, G. Bugmann, and D. J. Easterbrook, "Neural network design for engineering applications," Computers and Structures, vol. 79, no. 17, pp. 1541-1552, 2001.

[32] Y. C. Yeh, Application and Practice of Neural Networks, Rulin Publishing Company, 2009. 


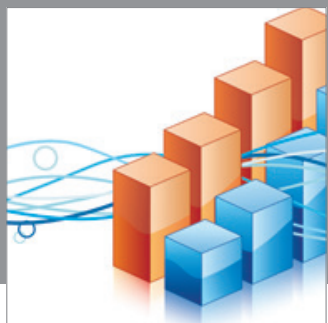

Advances in

Operations Research

mansans

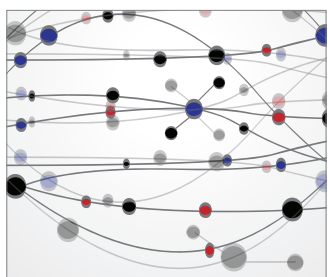

The Scientific World Journal
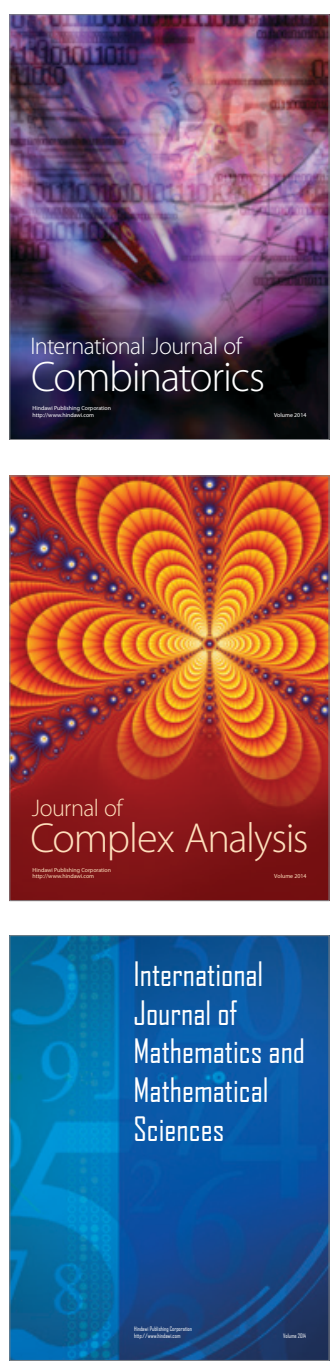
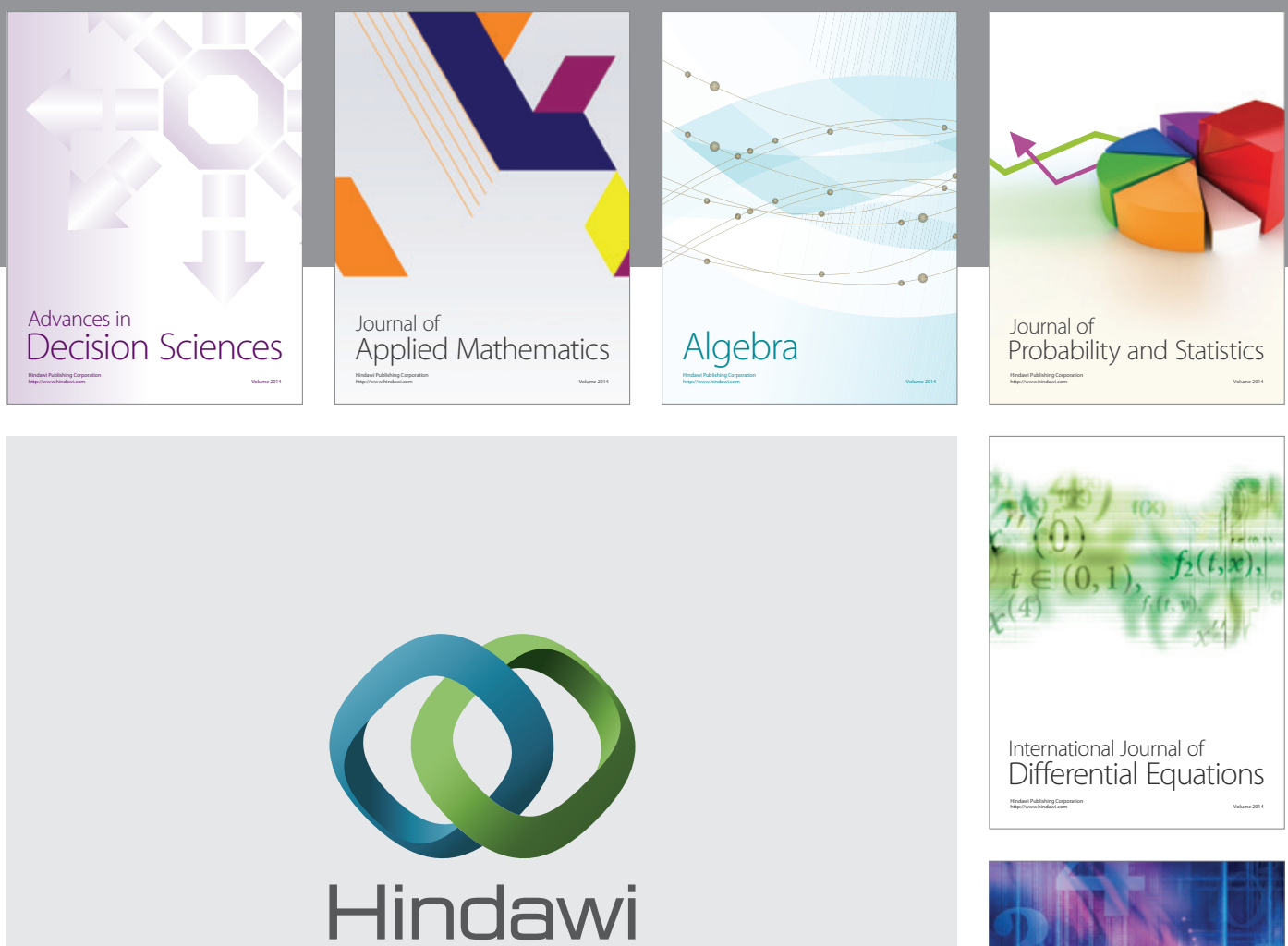

Submit your manuscripts at http://www.hindawi.com
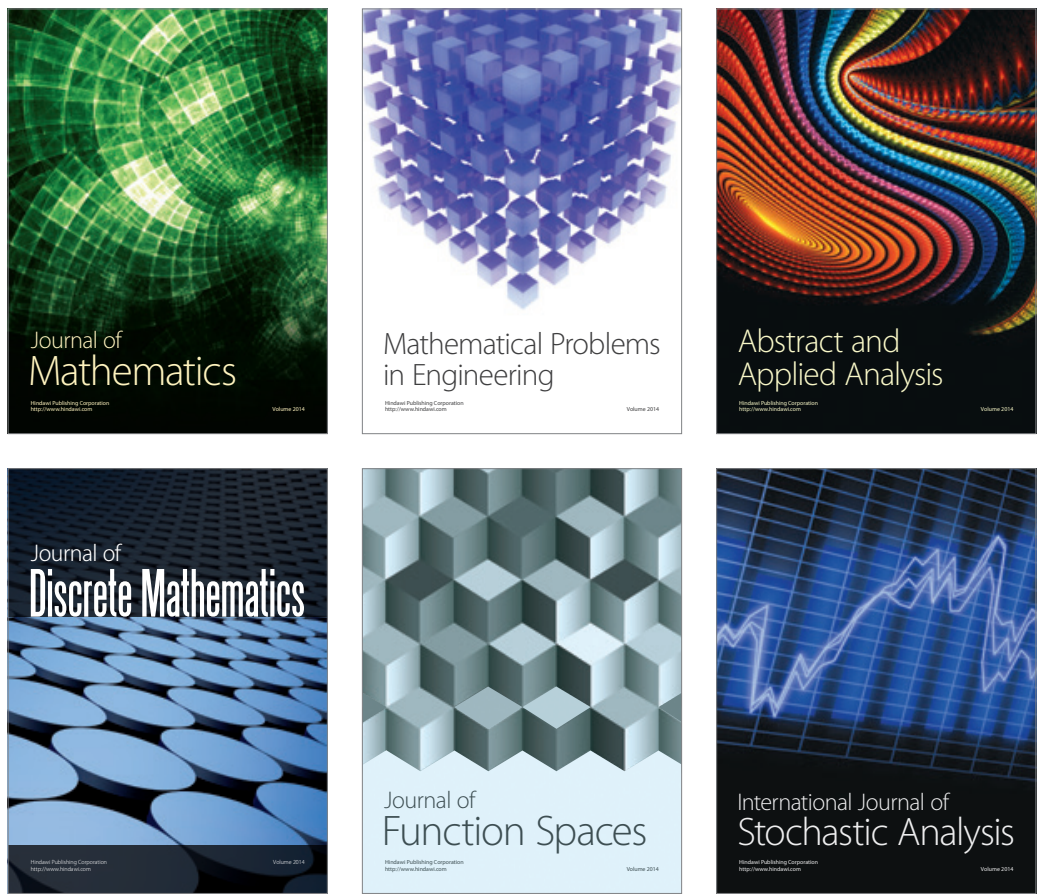

Journal of

Function Spaces

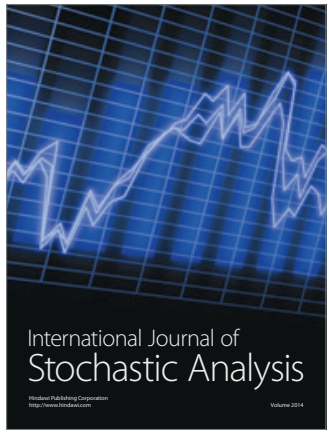

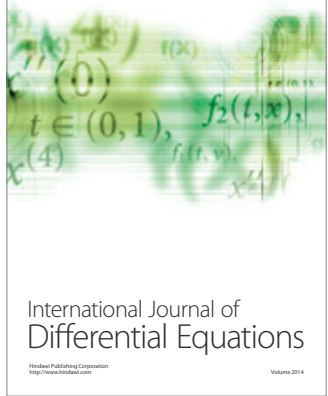
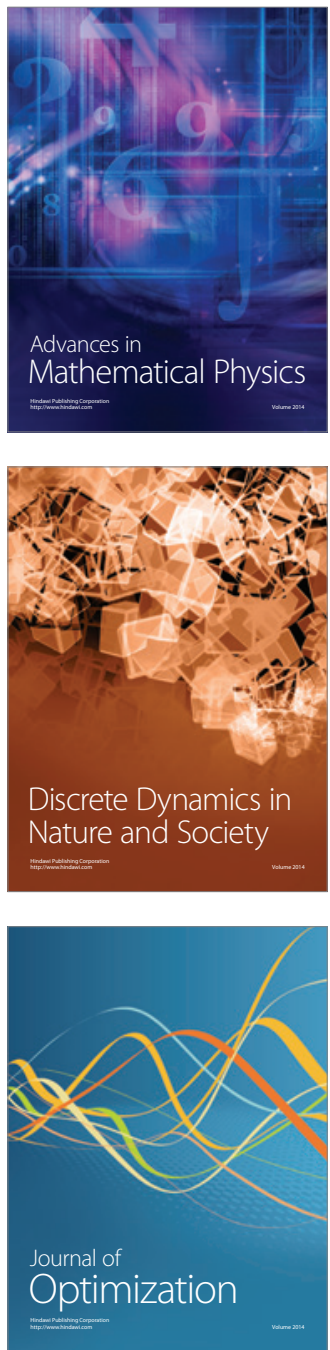